\title{
Erratum to: Risk-benefit assessment of closed intra-abdominal drains after pancreatic surgery: a systematic review and meta-analysis assessing the current state of evidence
}

\author{
Markus K. Diener • Keyvan Tadjalli-Mehr •
}

Moritz N. Wente • Meinhard Kieser •

Markus W. Büchler • Christoph M. Seiler

Published online: 15 March 2011

(C) Springer-Verlag 2011

Erratum to: Langenbecks Arch Surg (2011) 396:41-52

DOI 10.1007/s00423-010-0716-0

The original version of this article unfortunately contained a mistake. One of the authors' names was incorrectly captured. The author's correct name is Keyvan Tadjalli-Mehr.

The online version of the original article can be found at http://dx.doi. org/10.1007/s00423-010-0716-0.

M. K. Diener · M. N. Wente $\cdot$ M. W. Büchler $\cdot$ C. M. Seiler $(\bowtie)$

Department of General, Visceral and Transplantation Surgery,

University of Heidelberg,

Im Neuenheimer Feld 110,

69120 Heidelberg, Germany

e-mail: Christoph.Seiler@med.uni-heidelberg.de

M. K. Diener $\cdot$ M. N. Wente $\cdot$ C. M. Seiler

Study Centre of the German Surgical Society,

University of Heidelberg,

Im Neuenheimer Feld 110,

69120 Heidelberg, Germany

K. Tadjalli-Mehr $\cdot$ M. Kieser

Institute of Medical Biometry and Informatics,

University of Heidelberg,

Heidelberg, Germany 